University of Nebraska - Lincoln

DigitalCommons@University of Nebraska - Lincoln

Biochemistry -- Faculty Publications

Biochemistry, Department of

July 1999

\title{
Posttranscriptional Regulation of Mammalian Methionine Synthase by $\mathrm{B}_{12}$
}

\author{
Sumedha Gulati \\ University of Nebraska - Lincoln \\ Lawrence C. Brody \\ National Human Genome Institute, NIH, Bethesda, Maryland \\ Ruma V. Banerjee \\ University of Nebraska - Lincoln, rbanerjee1@unl.edu
}

Follow this and additional works at: https://digitalcommons.unl.edu/biochemfacpub

Part of the Biochemistry, Biophysics, and Structural Biology Commons

Gulati, Sumedha; Brody, Lawrence C.; and Banerjee, Ruma V., "Posttranscriptional Regulation of Mammalian Methionine Synthase by $B_{12}$ " (1999). Biochemistry -- Faculty Publications. 20.

https://digitalcommons.unl.edu/biochemfacpub/20

This Article is brought to you for free and open access by the Biochemistry, Department of at DigitalCommons@University of Nebraska - Lincoln. It has been accepted for inclusion in Biochemistry -- Faculty Publications by an authorized administrator of DigitalCommons@University of Nebraska - Lincoln. 


\title{
Posttranscriptional Regulation of Mammalian Methionine Synthase by $\mathrm{B}_{12}{ }^{1}$
}

\author{
Sumedha Gulati, ${ }^{*, 2}$ Lawrence C. Brody, $\dagger$ and Ruma Banerjee ${ }^{*, 3}$ \\ *Biochemistry Department, University of Nebraska, Lincoln, Nebraska 68588-0664; and †Genetics and \\ Molecular Biology Branch, National Human Genome Institute, NIH, Bethesda, Maryland 20892-4442
}

\begin{abstract}
Methionine synthase is one of two key enzymes involved in the removal of the metabolite, homocysteine. Elevated homocysteine levels constitute a risk factor for cardiovascular diseases and for neural tube defects. In cell culture, the activity of methionine synthase is enhanced several-fold by supplementation with its cofactor, $B_{12}$. The mechanism of this regulation is unknown, although it has been ascribed to a shift from apoenzyme to holoenzyme. Using sensitive assay techniques as well as a combination of Northern and Western analyses, we demonstrate that the effect of $B_{12}$ on induction of methionine synthase activity is paralleled by an increase in the level of the enzyme. These studies exclude conversion of apoenzyme to holoenzyme as a basis for activation that had been described previously. Since the mRNA levels do not change during the same period that the methionine synthase levels increase, regulation of this protein by its cofactor must be exerted posttranscriptionally. C 1999 Academic Press
\end{abstract}

Methionine synthase is one of two key enzymes at the homocysteine metabolic junction in mammalian cell physiology. Its action converts homocysteine, a toxic metabolite to methionine, and concomitantly releases the circulating form of folic acid, methyltetrahydrofolate $\left(\mathrm{CH}_{3}-\mathrm{H}_{4}\right.$ folate), to tetrahydrofolate $\left(\mathrm{H}_{4}\right.$ folate), that is then available for supporting DNA biosynthesis $(1,2)$. Elevated levels of homocysteine con-

\footnotetext{
${ }^{1}$ This work was supported by a grant from the National Institutes of Health (DK45776) to R.B. and a Predoctoral Fellowship to S.G. from the American Heart Association (Nebraska Affiliate).

${ }^{2}$ Present address: 638C, Guggenheim, Mayo Clinic and Foundation, Rochester, MN 55905.

${ }^{3}$ Corresponding author. Fax: (402) 472-7842. E-mail: rbanerje@ unlinfo2.unl.edu.

Abbreviations used: $\mathrm{CH}_{3}-\mathrm{H}_{4}$ folate, methyltetrahydrofolate; $\mathrm{H}_{4}$ folate, tetrahydrofolate; SSC, saline sodium citrate; PBS, phosphate buffered saline; EMEM, Eagle's minimum essential medium; DEPC, diethylpyrocarbonate; $\mathrm{OHB}_{12}$, hydroxycob(III)alamin; SDS, sodium dodecyl sulfate; MOPS, $N$-morpholinosulfonic acid.
}

stitute an independent and significant risk factor for cardiovascular diseases (3). In addition, elevated levels of homocysteine and low maternal levels of $B_{12}$ are correlated with neural tube defects $(4,5)$. Methionine synthase is thus an important housekeeping enzyme at the intersection of sulfur and one-carbon metabolism, and its regulation influences intracellular homocysteine and folate pools. The consequences of lowering homocysteine with vitamins are being measured in clinical intervention studies. Thus, elucidating the mechanism by which $B_{12}$ induces methionine synthase activity and thereby affects homocysteine pools may have an important bearing on these intervention studies.

Studies by Mangum and North almost thirty years ago on the regulation of mammalian methionine synthase in HEp-2 cells in culture revealed that supplementation of the medium with $B_{12}$ resulted in a thirtyfold elevation of enzyme activity (6). This was later extended to several other cell lines in which the $B_{12}-$ induced activation of methionine synthase ranged from 10 - to 30 -fold (7). In the initial experiments, homocysteine and vitamin $B_{12}$ replaced methionine and choline in the medium. Homocysteine was however found to have no effect on the activation of methionine synthase, since $B_{12}$ in the presence or absence of homocysteine yielded the same extent of stimulation (7). The activity of the only other mammalian $B_{12}$-dependent enzyme, methylmalonyl-CoA mutase, was unchanged upon supplementation of the medium with $\mathrm{B}_{12}(8)$.

Several alternative hypotheses can be considered to explain induction of methionine synthase activity by its cofactor, $B_{12}$. First, if intracellular $B_{12}$ concentration is limiting, increase in enzyme activity could be due to conversion of apoenzyme to holoenzyme. Second, $B_{12}$ may exert its regulation at the methionine synthase promoter resulting in increased transcription. Third, $\mathrm{B}_{12}$ may enhance translation of the methionine synthase mRNA, either by affecting the stability of the message or by increasing access of the message to the translation apparatus. Fourth, $\mathrm{B}_{12}$ may enhance the 
stability of methionine synthase thereby affecting its turnover in the cell. Finally, $B_{12}$ may induce one or more genes that in turn increases the level of methionine synthase either at a transcriptional or posttranscriptional level.

The recent cloning of the human methionine synthase cDNA (9-11) and the development of sensitive assays to measure the relative apo- and holoenzyme content of the enzyme (12-14) now permit evaluation of these alternative hypotheses. In this study, we have examined whether the induction of methionine synthase by $B_{12}$ is correlated with changes in the mRNA levels, protein levels or the percent holoenzyme. Our studies clearly point to a post-transcriptional mechanism of activation of methionine synthase that is dependent on the synthesis of new enzyme.

\section{MATERIALS AND METHODS}

Materials. EMEM and hydroxocobalamin were purchased from Sigma. Fetal calf serum was from Calbiochem. The RNeasy kit was from Qiagen and Hybond $\mathrm{N}+$ membrane was from Amersham. RNase free reagents (MOPS, SSC) were molecular biology grade and were purchased from 5 Prime $\rightarrow 3$ Prime. DEPC treated water was used for making up solutions for RNA studies. Cell lines, Cos-7 (SV40-transformed African Green Monkey kidney cells), HeLa (human cervical carcinoma cells), HepG2 (human hepatoblastoma cells), and 293 (transformed human kidney cells) cells were from ATCC, and $293 \mathrm{t}^{+}$(derivative of 293 expressing the $\mathrm{T}$ antigen) was from Mike Fudos (NIH). The actin probe was from an in vitro transcription kit from Ambion.

Cell culture. Cells were cultured in EMEM supplemented with $10 \%$ fetal bovine serum and maintained at $37^{\circ} \mathrm{C}, 5 \% \mathrm{CO}_{2}$. The concentration of folic acid and methionine in this medium are $2.3 \mu \mathrm{M}$ and $100 \mu \mathrm{M}$ respectively. The estimated concentration of $B_{12}$ in the unsupplemented medium is $\sim 125 \mathrm{pM}$, and is derived from the serum (15). For studies involving RNA isolation, confluent cells from 4 or 5 petri dishes $(150 \mathrm{~mm})$ were harvested and frozen in lysis solution and stored at $-80^{\circ} \mathrm{C}$ until further processing.

For studies involving protein analysis (enzyme assays or Western blots) cell monolayers were washed with PBS, collected by centrifugation and the pellet was washed twice with PBS prior to freezing at $-80^{\circ} \mathrm{C}$. For $B_{12}$ induction studies, cells were grown to subconfluency before replacement of the medium with fresh EMEM supplemented with $\mathrm{OHB}_{12}$ at a concentration of $5 \mathrm{mg} / \mathrm{L}$. The $\mathrm{B}_{12}$ concentration was chosen based on the dose response for methionine synthase activity that has been reported previously (15). For experiments in which methionine synthase activity, and protein and RNA levels were being determined simultaneously at fixed time points following $B_{12}$ addition $(0,24$, and $48 \mathrm{~h})$, a large number of plates were cultured in parallel. Cells from 3 or 4 petri dishes were used per time point for each of the protein and RNA determinations.

Methionine synthase assay using cell extracts. The cell extracts were prepared and anaerobic assays were performed essentially as described previously (13). The cell extracts for the assays were thawed immediately prior to their use. They were made anaerobic by gently passing $\mathrm{N}_{2}$ for 30 min over the extracts in $1.5 \mathrm{ml}$ eppendorf tubes sealed with red rubber septa. The amount of protein used in the assays ranged from $0.3 \mathrm{mg}$ to $0.6 \mathrm{mg}$. Protein concentrations were determined using the Bradford assay (BioRad) with bovine serum albumin as standard. One unit of activity is defined as the amount of protein required to synthesize one pmol of methionine $h^{-1}$ at $37^{\circ} \mathrm{C}$.
RNA isolation. RNA was isolated using the RNeasy kit as per the vendor's protocol (Qiagen). Aliquots $(20-30 \mu \mathrm{l})$ of RNA were stored at $-80^{\circ} \mathrm{C}$ until needed.

Northern analysis. RNA samples $(10-15 \mu \mathrm{g})$ were heated at $65^{\circ} \mathrm{C}$ for $5 \mathrm{~min}$ and then cooled immediately on ice prior to loading onto a $1 \%$ formaldehyde agarose gel. The gel was electrophoresed in RNase free 1X MOPS ( 25 volts for $\sim 20 \mathrm{~h}$ at $4^{\circ} \mathrm{C}$ ), equilibrated with $10 \mathrm{X} \mathrm{SSC}$ and transferred to a Hybond $\mathrm{N}+$ membrane in the same buffer. After overnight transfer, RNA was UV-linked to the membrane. Prehybridization and hybridizations were performed in Church and Gilbert hybridization buffer. Hybridization was conducted overnight at $65^{\circ} \mathrm{C}$ for $12 \mathrm{~h}$ (with $3 \times 10^{6} \mathrm{dpm}$ per $\mathrm{ml}$ radiolabeled probe). An NcoI-EcoRI fragment containing the homocysteine-binding domain in plasmid SGHcy-28a (described below) was used as one of the probes. Probes (for methionine synthase and actin) were radiolabeled with ${ }^{32} \mathbf{P}$ (Rediprime kit from Amersham Life Science). Following hybridization, the membrane was washed at $65^{\circ} \mathrm{C}$ for $3 \times 20 \mathrm{~min}$ with $2 \mathrm{X}$ SSC and $0.1 \%$ SDS. The membrane was exposed to a phosphoimager screen for 2-3 days at room temperature and then scanned.

Cloning and expression of homocysteine binding domain of human $M S$. The N-terminal region of human methionine synthase extending from amino acids 1 to 368 is homologous to the homocysteine binding domain of the $E$. coli protein ranging from residues 2-353 $(16,17)$. The segment of the human cDNA encoding this fragment was amplified by PCR and cloned using the primers described below. An NcoI site and an EcoRI site were engineered into the 5' sense and $3^{\prime}$ antisense primers respectively and are indicated in bold letters in the primer sequences shown below. $5^{\prime}$ sense: $5^{\prime}$ CATGCCATGGCTCCGGCGCTGCAGGACCTGTCGC $3^{\prime}$. $3^{\prime}$ antisense: 5' GAATTCAATGTTAACAAATTACTAGTACGGTCCAATCCT $3^{\prime}$. In the $5^{\prime}$ primer, the $E$. coli codon preference was employed at some locations to potentially enhance translation efficiency. The codon preference for amino acids following the initiator methionine codon located within the NcoI site (underlined in primer sequence) are indicated in parentheses: Met-Ala (E. coli)-Pro (E. coli)-Ala (human)-Leu (E. coli)Gln (E. coli)-Asp (human)-Leu (human)-Ser (human). In the $3^{\prime}$ primer, two tandem stop codons (underlined) were engineered into the sequence after residue 368 encoding tyrosine. A $1.1 \mathrm{~kb}$ fragment was amplified by PCR using Klentaq polymerase (Clonetech) and cDNA from human pancreas (Clonetech) as template. The amplified band was initially cloned into the TA vector, PCR 2.1 , from Invitrogen, and the ligation mixture was used to transform $E$. coli Top $10 \mathrm{~F}^{\prime}$ cells (Invitrogen). DNA from a single colony was digested with NcoI and EcoRI and the fragment was cloned into the pet 28 a expression vector (Novagen) to create SGHcy-28a, and transformed into BL21 DE3. The DNA sequence of the insert in SGHcy-28a was determined.

Expression of homocysteine binding domain of human methionine synthase. A colony containing plasmid SGHcy-28a with the $1.1 \mathrm{~kb}$ insert, was grown overnight in $2 \mathrm{ml} \mathrm{LB}$ medium (containing $50 \mu \mathrm{g} / \mathrm{ml}$ kanamycin) which was used to inoculate a $50 \mathrm{ml} \mathrm{LB} / \mathrm{kanamycin}$ culture the next day. The culture was grown at $37^{\circ} \mathrm{C}$ to an $O . D_{600}$ of 0.5-0.6 $(\sim 3 \mathrm{~h})$ and expression was induced with $0.8 \mathrm{mM}$ IPTG for $3 \mathrm{~h}$. Cells were collected by centrifugation and the pellet was resuspended in $3 \mathrm{ml}$ of $50 \mathrm{mM}$ Tris- $\mathrm{HCl} \mathrm{pH} 8.0,2 \mathrm{mM}$ EDTA. The soluble and insoluble cell fractions were obtained using a protocol from Novagen. Lysozyme at a concentration of $100 \mu \mathrm{g} / \mathrm{ml}$ and 0.1 volume of $1 \%$ Triton X-100 (Bio-Rad) were added to the resuspended pellet and incubated at $30^{\circ} \mathrm{C}$ for $15 \mathrm{~min}$. This was followed by centrifugation at $12,000 \mathrm{X}$ g for $15 \mathrm{~min}$ at $4^{\circ} \mathrm{C}$. The soluble (supernatant) and insoluble (pellet) fractions were resuspended in a 1X SDS sample loading buffer (Bio-Rad) containing $\beta$-mercaptoethanol, and separated by electrophoreses on a $10 \%$ SDS polyacrylamide gel (Figure $3 \mathrm{~A}$ ). The identity of the recombinant $37 \mathrm{kDa}$ band was confirmed by $\mathrm{N}$-terminal amino acid sequence analysis and by Western analysis using antibodies generated against porcine methionine synthase (12). DNA and N-terminal sequence analyses revealed that Glu 12 
TABLE I

Induction of Methionine Synthase Activity by $B_{12}$ in Cell Culture

\begin{tabular}{|c|c|c|c|c|c|c|c|}
\hline \multirow{3}{*}{$\begin{array}{l}\text { Medium: } \\
\text { Cell line }\end{array}$} & \multicolumn{3}{|c|}{ EMEM } & \multicolumn{4}{|c|}{ EMEM + B $_{12}$} \\
\hline & \multicolumn{2}{|c|}{ Specific activity } & \multirow[b]{2}{*}{$\%$ Holo } & \multicolumn{2}{|c|}{ Specific activity $^{a}$} & \multirow[b]{2}{*}{$\%$ Holo } & \multirow[b]{2}{*}{ Fold increase ${ }^{b}$} \\
\hline & $-\mathrm{B}_{12}$ & $+\mathrm{B}_{12}$ & & $-\mathrm{B}_{12}$ & $+\mathrm{B}_{12}$ & & \\
\hline $\operatorname{Cos} 7$ & $48 \pm 6$ & $72 \pm 5$ & 67 & $179 \pm 28$ & $271 \pm 4$ & 66 & 3.8 \\
\hline HeLa & $140 \pm 21$ & $163 \pm 12$ & 86 & $237 \pm 40$ & $320 \pm 6$ & 74 & 2.0 \\
\hline $293 t+$ & $52 \pm 9$ & $149 \pm 1$ & 35 & $883 \pm 1$ & $860 \pm 14$ & 103 & 5.8 \\
\hline HepG2 & $12 \pm 2$ & $15 \pm 2$ & 80 & $167 \pm 9$ & $205 \pm 6$ & 81 & 13.7 \\
\hline 293 & $99 \pm 6$ & $119 \pm 1$ & 83 & $218 \pm 6$ & $299 \pm 28$ & 73 & 2.5 \\
\hline
\end{tabular}

${ }^{a}$ Specific activity is expressed in pmol methionine formed $\min ^{-1} \mathrm{mg}^{-1}$ at $37^{\circ} \mathrm{C}$.

${ }^{b}$ The fold increase was estimated by comparing the values for specific activities measured in the presence of added $B_{12}$.

was deleted. This could have resulted from a polymorphism at this position that was present in the cDNA library or, more likely, from a PCR error.

Generation of antibodies against the human methionine synthase. The pellet containing the insoluble $\mathrm{N}$-terminal domain of human methionine synthase was washed extensively with $50 \mathrm{mM}$ Tris, $\mathrm{pH}$ 8.0 containing $2 \mathrm{mM}$ EDTA. The washed pellet $(\sim 1.5 \mathrm{mg})$ was separated on a preparative $7 \%$ SDS polyacrylamide gel and the band of interest was excised after staining with Coommasie brilliant blue R-250 (Bio-Rad) followed by extensive destaining. The excised band was sent to a commercial antibody facility (Alpha Diagnostics, Texas) for generation of polyclonal antibodies in rabbits.

Western analysis of human methionine synthase in cells cultured in medium $\pm B_{12}$. Extracts (50 $\mu \mathrm{g}$ protein), from cells grown in EMEM medium supplemented with $B_{12}$ for 0,24 and $48 \mathrm{~h}$, were separated on a 5\% SDS polyacrylamide gel. The proteins were transferred to a PVDF membranes using a tank electroblotter for $6 \mathrm{~h}$ at $100 \mathrm{~V}$. Western analysis was performed using a 1:100 dilution of the first antibody and a 1:5000 dilution of the second antibody, anti-rabbit IgG/alkaline phosphatase conjugate (BioRad), followed by chemiluminescent detection using the CDP-Starr kit (Tropix). Chemiluminescent signals were quantitated using a Molecular Dynamics densitometer.

\section{RESULTS}

Induction of methionine synthase activity by $B_{12}$ is not due to apoenzyme to holoenzyme conversion. In order to examine whether or not activation by $\mathrm{B}_{12}$ is due to conversion of apoenzyme to holoenzyme, the effect of $B_{12}$ addition to the cell culture medium was examined in five different cell lines (Table I). Enzyme activity was measured in the anaerobic titanium citrate assay either in the presence or absence of exogenous $B_{12}$. Activity determined in the presence of $B_{12}$ represents total methionine synthase activity. In the absence of $\mathrm{B}_{12}$, only holoenzyme activity is measured. Thus the ratio of activity observed in the absence to that in the presence of additional cofactor represents the proportion of holoenzyme present. As shown in Table I, all five cells lines showed stimulation of methionine synthase activity when the medium was supplemented with $B_{12}$. The fold increase varied with the cell line, ranging from 2-fold in HeLa cells to $\sim 14$-fold in HepG2 cells. Increasing the concentration of the cofactor ten-fold did not further increase the foldinduction (data not shown). Comparison of enzyme activity from cells that had been supplemented with $B_{12}$ with those grown in unsupplemented media show that the proportion of holoenzyme remained the same, within experimental error. The only exception was $293 \mathrm{t}^{+}$cells where the holoenzyme content increased from $34 \%$ to $100 \%$. However, the 3 -fold increase in percent holoenzyme does not account for the almost 6-fold increase in methionine synthase activity resulting from $\mathrm{B}_{12}$ supplementation. 293 cells were employed for the remainder of the studies described below because of their high holoenzyme content and rapid growth rate.

Kinetics of methionine synthase induction by $B_{12}$. The time course for the activation of methionine synthase was examined next. As shown in Figure 1, increase in methionine synthase activity could be observed as early as two hours following $B_{12}$ addition. The activity increased rapidly during the first six hours reaching a plateau in $\sim 24$ to $48 \mathrm{~h}$ and was sustained until $72 \mathrm{~h}$.

$B_{12}$ supplementation does not change methionine synthase RNA levels. To examine whether the $\mathrm{B}_{12}$ effect is due to transcriptional activation of the methionine synthase gene, mRNA levels were analyzed 0,24 and $48 \mathrm{~h}$ after addition of the cofactor (Figure 2A). Two methionine synthase mRNA's of $\sim 10$ and $7.5 \mathrm{~kb}$ sizes were observed by Northern analysis as has been reported previously $(9,11)$. However, the level of methionine synthase mRNA remained unchanged during the same period that a 2.5 -fold increase in enzyme activity was observed. Equal loading of RNA in the three lanes was confirmed by probing for the actin message (Figure 2B). Northern analysis of three other cell lines (Cos7, HepG2 and $293 \mathrm{t}^{+}$) also revealed that the methionine synthase mRNA levels do not change upon $\mathrm{B}_{12}$ supplementation (data not shown). 


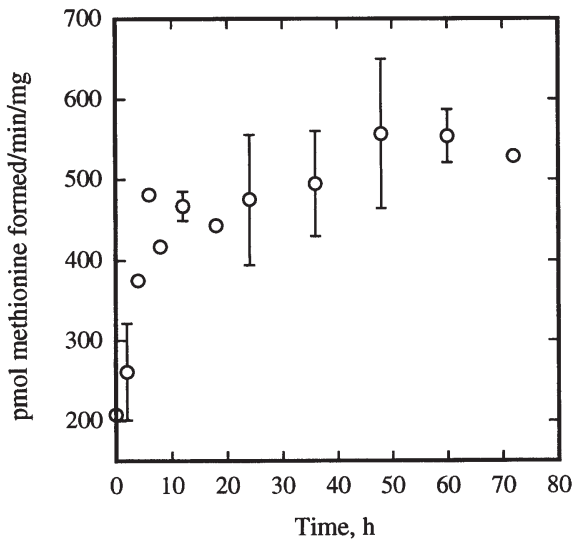

FIG. 1. Kinetics of methionine synthase induction in 293 cells by $B_{12}$. Cells were grown to subconfluency in $150 \mathrm{~mm}$ petridishes as described under Materials and Methods. The medium was aspirated off and replaced with fresh EMEM with either $\pm \mathrm{B}_{12}$. The cells were harvested by scraping at the indicated time points and frozen until further analysis. Methionine synthase activity was determined in the anaerobic titanium citrate assay in the absence of additional cobalamin. The time points were repeated in either duplicate or triplicate, and standard errors are indicated.

Western analysis of methionine synthase levels in cell cultures exposed to $B_{12}$. Cell extracts from the 0, 24 and $48 \mathrm{~h}$ time points were analyzed by Western blotting. As shown in Figure 3B, an increase in methionine synthase level is observed between the 0 and $24 \mathrm{~h}$ time points, while the difference between the 24 and $48 \mathrm{~h}$ time points is negligible. To ensure equal loading, the membrane was also exposed to antibody generated against the $P$. shermanii methylmalonyl-CoA mutase. As expected, the levels of this protein did not exhibit a time dependent change (Figure 3B lower panel). An additional lower band also crossreacted with the mutase antibody. Although its identity is unknown (it may be a proteolytic form), it serves as an additional control to demonstrate that a specific increase in methionine synthase levels is observed on supplementation of the medium with $\mathrm{B}_{12}$.

\section{DISCUSSION}

Elevated concentrations of homocysteine are correlated with risk for two apparently unrelated pathologies: cardiovascular diseases (3) and neural tube defects (5). In mammalian cells, two major enzymatic routes detoxify homocysteine. Transmethylation, catalyzed by either methionine synthase or betaine homocysteine methyltransferase, salvages homocysteine to the AdoMet-dependent methylation cycle. Transsulfuration, catalyzed by cystathionine $\beta$-synthase converts homocysteine to cystathionine, and represents the first step in its catabolic removal. Due to the limited tissue distribution of betaine homocysteine methyltransferase in the liver and kidney (18), methionine synthase is the major transmethylase. A

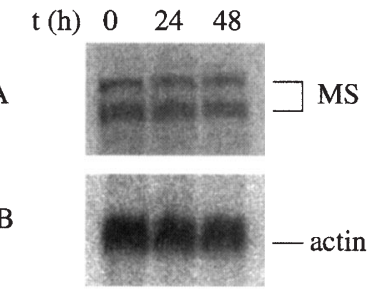

FIG. 2. Northern blot analysis of RNA from 293 cells, 0 , 24, and $48 \mathrm{~h}$ after addition of $\mathrm{B}_{12}$. RNA was isolated and detected by Northern blot analysis as described under Materials and Methods. (A) Two bands corresponding to the $\sim 10 \mathrm{~kb}$ and $7.5 \mathrm{~kb}$ methionine synthase cDNA forms were observed. (B) To confirm equal loading of RNA in the lanes, the blot was later probed for the actin message.

number of nutrients function as cofactors or substrates at the homocysteine metabolic junction. Cystathionine $\beta$-synthase is a vitamin $\mathrm{B}_{6}$ - and heme-dependent enzyme whereas methionine synthase requires both $\mathrm{B}_{12}$ and a folate derivative, $\mathrm{CH}_{3}-\mathrm{H}_{4}$ folate, for activity. This has recently led to the promotion of a multivitamin tablet containing $\mathrm{B}_{6}, \mathrm{~B}_{12}$, and folic acid as a "homocysteine defense"

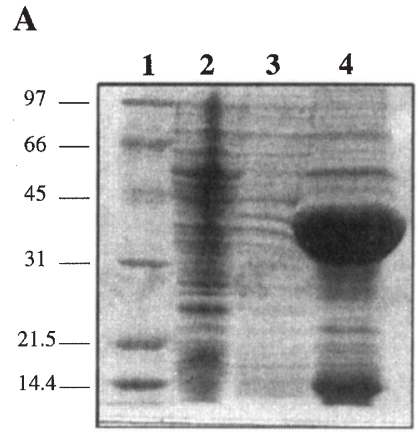

B

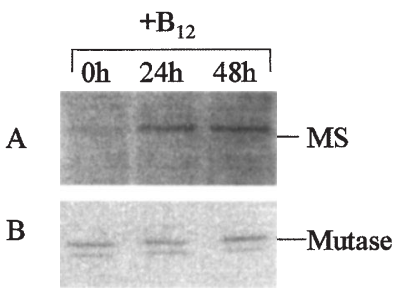

FIG. 3. Overexpression of human methionine synthase fragment and Western analysis of methionine synthase at various time points following addition of $\mathrm{B}_{12}$. (A) Overexpression of the homocysteinebinding domain of human methionine synthase. Cell extracts containing SGHcy-28a were prepared as described under Materials and Methods. Lane 1 has low molecular weight markers, lane 2 has cell extract after sonication, lanes 3 and 4 have the soluble and insoluble fractions respectively separated from the cell extract. (B) Western analysis of methionine synthase levels in the 293 cell extracts at the indicated time points. As a control, the membrane was also probed with antibodies generated against methylmalonyl-CoA mutase from Propionibacterium shermanii. The band indicated by an arrow corresponds to the human mutase. MS refers to methionine synthase. The sizes of the molecular weight markers (in $\mathrm{kDa}$ ) are indicated on the left. 
formula, and to folic acid fortification of flour in the U.S. in an effort to reduce the incidence of neural tube defects. Homocysteine lowering intervention studies using different vitamin regimens are either imminent or ongoing in several countries.

Understanding the role of cofactors in regulating the activities of enzymes at the homocysteine metabolic junction is therefore of importance from a clinical standpoint. One of these cofactors, $\mathrm{B}_{12}$, was described thirty years ago, to induce activity of methionine synthase in cell culture (6). In this study we have also observed that $\mathrm{B}_{12}$-induces a 2 to 14 -fold increase in methionine synthase activity in different cell lines. The mechanism by which exogenous $B_{12}$ in the cell culture medium causes an increase in methionine synthase activity was previously unknown, although it had been ascribed to conversion of preexisting apoenzyme to holoenzyme $(8,15)$.

However, evaluation of the percent holomethionine synthase is complicated by its existence in multiple oxidation states, containing $\mathrm{B}_{12}$ as methylcob(III)alamin, hydroxycob(III)alalmin or cob(II)alamin. Of these, only the first is active under in vitro assay conditions, and then only, for a limited number of turnovers (100-2000 depending on the degree of anaerobiocity $(19,20)$ ). This results from the oxidative sensitivity of the cofactor intermediate, cob(I)alamin, under catalytic turnover conditions. The oxidized forms of the enzyme can be reactivated in the presence of a one electron donor and S-adenosylmethionine. The standard in vitro assay employs dithiothreitol and $\mathrm{OHB}_{12}$ as a source of electrons. In the absence of $\mathrm{OHB}_{12}$, dithiothreitol is unable to transfer electrons to methionine synthase (21). The problem with this assay arises from its dependence on $\mathrm{OHB}_{12}$, which serves both to transfer electrons from dithiothreitol to activate oxidized holoenzyme and binds to apoenzyme, eventually converting it to holoenzyme (12). Thus, the complexity of the methionine synthase assay has resulted in significant underestimation of the holoenzyme content in the literature.

This problem is addressed by employing titanium citrate as the electron donor since it can directly reduce methionine synthase (12). Under these assay conditions, the relative content of apo- and holoenzyme can be evaluated by measuring activity in the presence and absence of exogenous $\mathrm{OHB}_{12}$. Using this assay, we demonstrate that the increase in methionine synthase activity is not correlated with conversion of apoenzyme to holoenzyme (Table I). In fact in four of the five cell lines, addition of $B_{12}$ to the cell culture medium does not affect the level of holomethionine synthase at all. One exception, $293 \mathrm{t}^{+}$cells, show a 3 -fold increase in holoenzyme under these conditions, although this is insufficient to account for the 5.7-fold increase observed in methionine synthase activity. These results necessitate evaluation of alternative mechanisms to

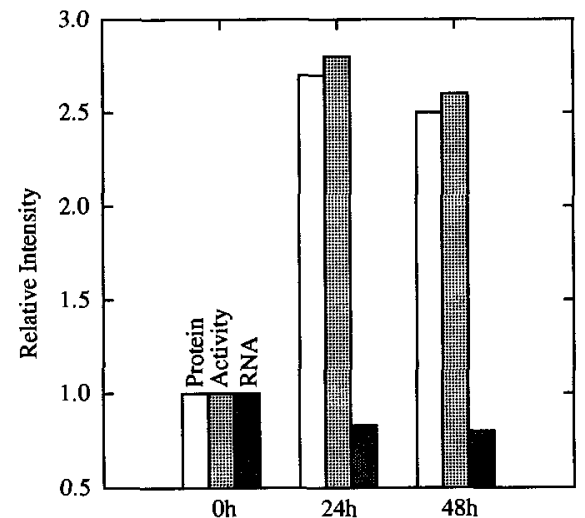

FIG. 4. Comparison of the methionine synthase activity and RNA and protein levels at the indicated time points following addition of $B_{12}$ to the medium.

account for $B_{12}$ induction of methionine synthase activity.

The recent cloning of the human methionine synthase cDNA permits direct evaluation of the mRNA levels as a function of time following exposure to $B_{12}$. In order to choose appropriate time points for this analysis, the kinetics of methionine synthase induction were studied in the 293 cell line. As shown in Figure 1, maximal activation is observed in $\sim 24 \mathrm{~h}$, and this level is sustained up to $72 \mathrm{~h}$. This is very similar to the kinetics reported in cultured BHK cells (15). Based on these data, we compared the mRNA and protein levels at 0,24 and $48 \mathrm{~h}$ following $\mathrm{B}_{12}$ addition to the cell culture medium (Figure 3 ). Comparison of the ratio of methionine synthase mRNA to actin mRNA indicates that the level of the methionine synthase mRNA remains fairly constant over $48 \mathrm{~h}$ (Figure 4) during which time enzyme activity increases 2.5 -fold. The two RNA bands that hybridize to the methionine synthase probe have been observed previously $(9,11)$. The shorter cDNA has been sequenced completely (9). The $10 \mathrm{~kb}$ band is apparently a preprocessed form of the $7.5 \mathrm{~kb}$ message, since it hybridizes to a probe complementary to intron 5 (11).

Since activation of methionine synthase levels was reported to be due to conversion of apoenzyme to holoenzyme we have directly estimated the relative levels of methionine synthase protein in the presence and absence of added $\mathrm{B}_{12}$. As seen in Figures $3 \mathrm{~B}$ and 4 , an increase in the steady-state concentration of methionine synthase parallels the increase in its activity. It was previously reported that $B_{12}$ induction of methionine synthase activity was not affected by the presence of the translation inhibitor, puromycin, added simultaneously with $B_{12}$ to the cell culture medium (15). However, these results were inconsistent with the kinetics of $\mathrm{B}_{12}$ activation in the $\mathrm{BHK}$ cell lines reported in the same paper, since in the presence of puromycin, full activation was observed in $12 \mathrm{~h}$ rather than in $24 \mathrm{~h}$. 
Additionally, $\mathrm{B}_{12}$ has a very high affinity transport system, it is possible that the rate of $B_{12}$ import was more rapid than that of puromycin, resulting in a delayed effect of puromycin. In contrast, western analysis permits a more direct evaluation of methionine synthase levels, and demonstrates unambiguously that a new protein synthesis is required for activation by $B_{12}$.

At least two alternative hypotheses can be considered to explain the mechanism of $B_{12}$ induced activation of methionine synthase. First, the intracellular $B_{12}$ pool increases upon supplementation of the medium and a higher proportion of newly synthesized methionine synthase is stabilized by binding cofactor. While our data do not rule this out, it seems unlikely since the levels of holoenzyme do not change significantly in most cell lines. For example $66 \%$ of methionine synthase in Cos 7 cells is present in the holoenzyme form regardless of whether or not the medium is supplemented with the cofactor. If stabilization of methionine synthase by an increased intracellular $B_{12}$ pool resulted in the increase in its steady-state levels, the percentage of holoenzyme would have been expected to be increased.

Alternatively, methionine synthase could be translationally regulated by its cofactor. Two other folatedependent enzymes, dihydrofolate reductase and thymidylate synthase (22-24), bind to their own mRNAs. This represses translation and represents a form of autoregulation. Binding of the nucleotide substrate (dUMP in thymidylate synthase) or cofactor (NADPH in dihydrofolate reductase) competes with binding for mRNA and alleviates translation inhibition. This has led to the suggestion that the nucleotide binding domains of RNA-binding proteins may have acquired enzymatic activity (or the converse) during evolution (25). It is interesting to note that $B_{12}$ also has a nucleotide moiety, with an unusual base, dimethylbenzimidazole, that is appended from ring $\mathrm{D}$ of the corrin macrocycle.

Vitamin $B_{12}$ has been shown to mediate repression of gene expression in E. coli and in Salmonella typhimurium. In the latter organism, expression of the cob operon involved in the de novo biosynthesis of $B_{12}$ is repressed (26-28). In both $E$. coli and in S. typhimurium, $\mathrm{B}_{12}$ represses the btu $\mathrm{B}$ gene product encoding an outer membrane $B_{12}$ transport protein $(29,30)$. Studies on the mechanism of this repression reveal that it is mediated postranscriptionally (31). A 25 bp long regulatory sequence designated as the $B_{12}$ box is located $\sim 80-110$ bp upstream of the initiation codon, and has been suggested to constitute the binding site of $B_{12}$ itself or a $B_{12}$ responsive protein (27). In addition, a second common element observed in these transcripts is the presence of sequences in the leader with the potential to form an RNA hairpin which sequesters the RNA binding site. In the presence of $B_{12}$ an RNA hairpin forms with inhibits translation initiation of the cbiA gene in S. typhimurium (28). Since the regulatory elements for translation are distinct in prokaryotes and eukaryotes, it is not surprising that a consensus $B_{12}$ box is not observed in the human methionine synthase cDNA.

In summary, our data exclude both conversion of apomethionine synthase to holoenzyme and transcriptional activation as explanations for the observed induction of methionine synthase activity by its cofactor, $\mathrm{B}_{12}$. Instead, our data demonstrate that induction of methionine synthase activity correlates with increased levels of protein, and is therefore exerted at a posttranscriptional level. Elucidation of the mechanism of $\mathrm{B}_{12^{-}}$ mediated posttranscriptional regulation will be the subject of future investigation.

\section{REFERENCES}

1. Banerjee, R. (1997) Chemistry and Biology 4, 175-186.

2. Ludwig, M. L., and Matthews, R. G. (1997) Annu. Rev. Biochem. 66, 269-313.

3. Refsum, H., Ueland, P. M., Nygard, O., and Vollset, S. E. (1998) Annu. Rev. Medicine 49, 31-62.

4. Kirke, P. N., Molloy, A. M., Daly, L. E., Burke, H., Weir, D. G., and Scott, J. M. (1993) Quarterly J. Med. 86, 703-7708.

5. Mills, J. L., McPartlin, J. M., Kirke, P. N., Lee, Y. J., Conle, M. R., and Weir, D. G. (1995) Lancet 345, 149-151.

6. Mangum, J. H., and North, J. A. (1968) Biochem. Biophys. Res. Commun. 32, 105-110.

7. Mangum, J. H., Murray, B. K., and North, J. A. (1969) Biochemistry 8, 3496-3499.

8. Kerwar, S. S., Spears, C., Brian, M., and Weissbach, H. (1971) Arch. Biochem. Biophys. 142, 231-237.

9. Li, Y. N., Gulati, S., Baker, P. J., Brody, L. C., Banerjee, R., and Kruger, W. D. (1996) Hum. Molec. Genetics 5, 1851-1858.

10. Leclerc, D., Campeau, E., Goyette, P., Adjalla, C. E., Christensen, B., Ross, M., Eydoux, P., Rosenblatt, D. S., Rozen, R., and Gravel, R. A. (1996) Hum. Molec. Genet. 5, 1867-1874.

11. Chen, L. H., Liu, M.-L., Hwang, H.-Y., Chen, L.-S., Korenberg, J., and Shane, B. (1997) J. Biol. Chem. 272, 3628-3634.

12. Chen, Z., Chakraborty, S., and Banerjee, R. (1995) J. Biol. Chem. 270, 19246-19249.

13. Gulati, S., Brody, L. C., Rosenblatt, D. S., and Banerjee, R. (1997) J. Biol. Chem. 272, 19171-19175.

14. Banerjee, R., Gulati, S., and Chen, Z. (1997) Methods Enzymol. 281, 189-196.

15. Kamely, D., Littlefield, J. W., and Erbe, R. W. (1973) Proc. Natl. Acad. Sci. USA 70, 2585-2589.

16. Goulding, C. W., and Matthews, R. G. (1997) Biochemistry 36, 15749-15757.

17. Goulding, C. W., Postigo, D., and Matthews, R. G. (1997) Biochemistry 36, 8082-8091.

18. Finkelstein, J. D., and Martin, J. J. (1984) J. Biol. Chem. 259(15), 9508-9513.

19. Fujii, K., and Huennekens, F. M. (1974) J. Biol. Chem. 249, 6745-6753.

20. Drummond, J., Huang, S., Blumenthal, R. M., and Matthews, R. G. (1993) Biochemistry 32, 9290-9295.

21. Chen, Z., Crippen, K., Gulati, S., and Banerjee, R. (1994) J. Biol. Chem. 269, 27193-27197.

22. Chu, E., Koeller, D. M., Casey, J. L., Drake, J. C., Chabner, B. A., 
EWlwood, P. C., Zinn, S., and Allegra, C. J. (1991) Proc. Natl. Acad. Sci. USA 88, 8977-8981.

23. Chu, E., Voeller, D., Koeller, D. M., Drake, J. C., Takimoto, C. H., Maley, G. F., Maley, F., and Allegra, C. J. (1993) Proc. Natl. Acad. Sci. USA 90, 517-521.

24. Chu, E., Takimoto, C. H., Voeller, D., Grem, J. L., and Allegra, C. J. (1993) Biochemistry 32, 4756-4760.

25. Hentze, M. W. (1994) Trends Biochem. Sci. 19, 101-103.

26. Escalante-Semerena, J. C., and Roth, J. R. (1987) J. Bacteriol. 169, 2251-2258.
27. Richter-Dahlfors, A. A., and Andersson, D. I. (1992) Mol. Microbio. 6, 743-749.

28. Richter-Dahlfors, A. A., and Ravnum, S., A., D. I. (1994) Mol. Microbiol. 13, 541-553.

29. Aufrere, R., Tempete, M., and Bohin, J.-P. (1986) Mol. Gen. Genet. 205, 358-365.

30. Lundrigan, M. D., Ksster, W., and Kadner, R. J. (1991) Proc. Natl. Acad. Sci. USA 88, 1479-1483.

31. Ravnum, S., and Andersson, D. I. (1997) Mol. Microbiol. 23, $35-42$. 